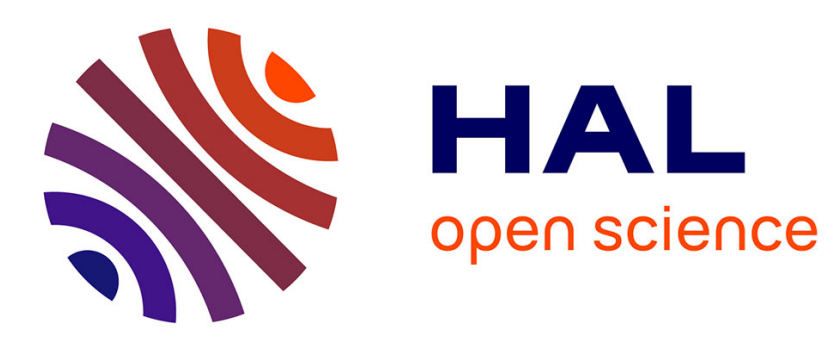

\title{
Antiferroelectric liquid crystals
}

Ludovic Benguigui, F. Hardouin

\section{To cite this version:}

Ludovic Benguigui, F. Hardouin. Antiferroelectric liquid crystals. Journal de Physique Lettres, 1981, 42 (16), pp.381-383. 10.1051/jphyslet:019810042016038100 . jpa-00231952

\section{HAL Id: jpa-00231952 https://hal.science/jpa-00231952}

Submitted on 1 Jan 1981

HAL is a multi-disciplinary open access archive for the deposit and dissemination of scientific research documents, whether they are published or not. The documents may come from teaching and research institutions in France or abroad, or from public or private research centers.
L'archive ouverte pluridisciplinaire HAL, est destinée au dépôt et à la diffusion de documents scientifiques de niveau recherche, publiés ou non, émanant des établissements d'enseignement et de recherche français ou étrangers, des laboratoires publics ou privés. 


\title{
Antiferroelectric liquid crystals
}

\author{
L. Benguigui \\ Solid State Institute, Technion-Israel Institute of Technology, Haifa, Israel \\ and F. Hardouin \\ Centre de Recherche Paul-Pascal, Université Bordeaux I, 33405 Talence Cedex, France
}

(Reçu le 27 avril 1981, accepté le 22 juin 1981)

\begin{abstract}
Résumé. - Des mesures diélectriques ont été effectuées sur deux systèmes cristaux liquides thermotropes qui présentent une phase smectique A2 (c.-à -d. dont l'épaisseur des couches est égale à deux fois la longueur de la molécule). L'hypothèse d'un ordre antiferroélectrique est compatible avec ces résultats. Des anomalies des constantes diélectriques $\varepsilon_{\|}$et $\varepsilon_{\perp}$ sont observées à la transition $\mathrm{N}-\mathrm{S}_{\mathrm{A} 2}$ et une relaxation basse fréquence inhabituelle, dépendant peu de la température, est également mise en évidence près de cette transition ainsi que dans les différentes phases $S_{A}$ de ces systèmes.
\end{abstract}

\begin{abstract}
Dielectric investigations have been undertaken in two thermotropic liquid crystal systems exhibiting a smectic A2 phase (i.e. with the layer spacing equal to twice the molecular length). The postulated antiferroelectric ordering has been supported by these measurements. There are anomalies in the dielectric constants $\varepsilon_{\|}$and $\varepsilon_{\perp}$ at the $\mathrm{N}-\mathrm{S}_{\mathrm{A} 2}$ transition and an unusual low frequency relaxation, with a slight temperature dependence, appears around this transition and in the $S_{A}$ phases of these systems.
\end{abstract}

The liquid crystal phases of the cyano compounds can exhibit very unusual properties such as the partially bilayer structure of the smectic $A$ phases [1], the reentrant phenomena [2], the $S_{A}-S_{A}$ transitions [3].

To explain some of these properties one assumed antiparallel association of molecules in pair with an overlapping of the rigid parts [4]. However, it is not sure that one can really speak about pairs of polar molecules (since there are no $\mathrm{NaCl}$ molecules in $\mathrm{NaCl}$ crystal) and it is better to introduce the concept of antiferroelectric ordering as specified by J. Prost [5]. Such an ordering should be observable in the dielectric properties of the compound 4-n hexylphenyl 4'cyanobenzoyloxy benzoate (DB6) with the following formula :

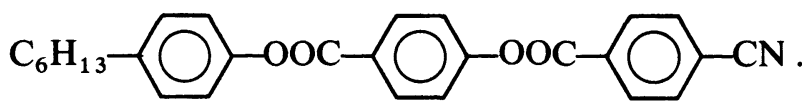

Indeed in this compound, one encounters an interesting situation : the smectic phase is a true «bimolecular " smectic A2 with a layer spacing $d$ quasi equal to two molecular lengths $l(d \simeq 1.95 l)$. Adding terephtal-bis-butyl aniline (TBBA) with increasing temperature, a $S_{A}-S_{A}$ phase transition arises giving a smectic Al with a half-layer spacing (i.e. a «monomolecular » $\left.\mathrm{S}_{\mathrm{A}}\right)[6]$.

From X-ray measurements F. Hardouin et al. [7] concluded that such a $\mathrm{S}_{\mathrm{A} 2}$ is the result of a true longrange antiferroelectric ordering. This long-range ordering in the direction of the long molecular axis has to be distinguished from the local antiferroelectric ordering which is generally assumed [8] to explain the dielectric properties of the $S_{A}$ phases. Thus we expect in DB6 compound a different behaviour of the dielectric properties, in particular an anomaly at the $\mathrm{N}-\mathrm{S}_{\mathbf{A} 2}$ transition.

The results we report in this communication are the dielectric constants at $20 \mathrm{kHz}$ (which can be considered as quasi-static permittivity) and the dielectric relaxations in the range $100 \mathrm{kHz}-100 \mathrm{MHz}$ of two systems. The first is the pure DB6 $\left(\mathrm{N}-\mathrm{S}_{\mathrm{A} 2}\right.$ transition at about $\left.165^{\circ} \mathrm{C}\right)$ and the second is a mixture of DB6 and TBBA (18 m. \% of this last compound) with the following transition temperature : $\mathrm{N}-\mathrm{S}_{\mathrm{A} 1}$ at $149^{\circ} \mathrm{C}$ and $\mathrm{S}_{\mathrm{A} 1}-\mathrm{S}_{\mathrm{A} 2}$ at $137^{\circ} \mathrm{C}$.

Depending on the measuring frequency, we have used the automatic bridge LC 1688 or General Radio $(240-20000 \mathrm{~Hz})$, the Q-meter of Boonton $(50 \mathrm{kHz}-$ $50 \mathrm{MHz}$ ) and the impedance meter of Hewlett Packard 
(0.5-100 MHz). The samples are orientated in the nematic phase by a magnetic field of $13 \mathrm{kG}$.

In figures 1 and 2 , we give the variations of $\varepsilon_{\|}$and $\varepsilon_{\perp}$ with the temperature $T$, below $190^{\circ} \mathrm{C}$ which is the upper temperature of our cell. This means that we can do measurements only slightly above the $\mathrm{N}-\mathrm{S}_{\mathrm{A} 2}$ transition temperature. We notice the maxima in both dielectric constants at the $\mathrm{N}-\mathrm{S}_{\mathrm{A} 2}$ transition. But at the $\mathrm{S}_{\mathrm{A} 1}-\mathrm{S}_{\mathrm{A} 2}$ transition, we have only a change in the slope.

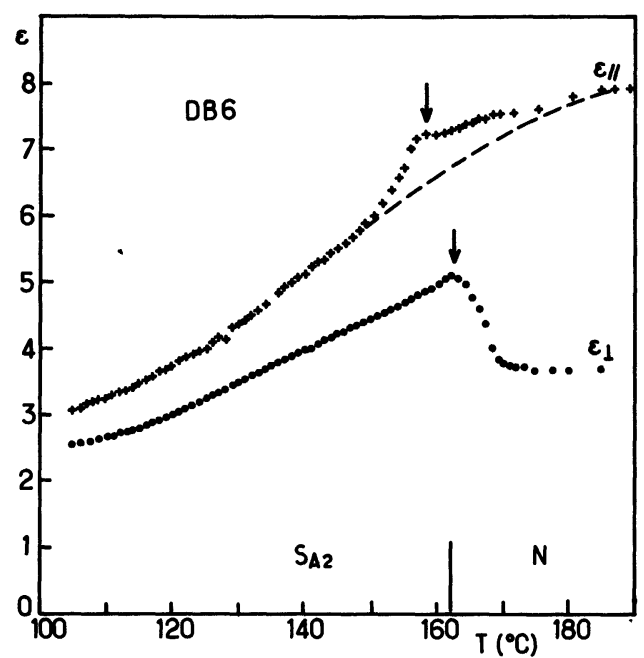

Fig. 1. - Variation of $\varepsilon_{\|}$and $\varepsilon_{\perp}$ of DB6 with the temperature.

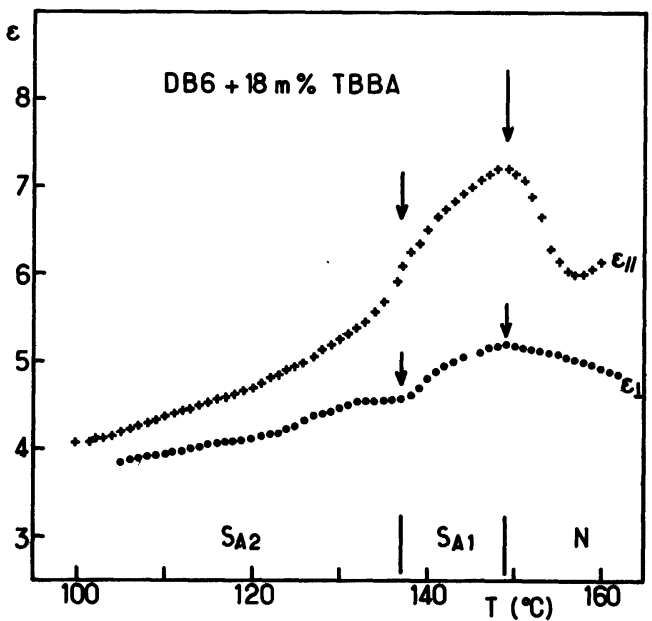

Fig. 2. - Variation of $\varepsilon_{\|}$and $\varepsilon_{\perp}$ of the DB6-18 $\mathrm{m} \%$ TBBA mixture.

It is not clear why the anomaly of $\varepsilon_{\perp}$ is stronger than that of $\varepsilon_{\|}$for DB6 and in the mixture DB6-TBBA it is the contrary. The values of $\varepsilon_{\perp}$ in the nematic phase are comparable to these observed in other cyano compounds (like for example in the cyano biphenyls $[10]$ in the compound 4-n octyloxybenzoyloxy 4'cyanostilbene [11]). But the values of $\varepsilon_{\|}$are much lower than these of the quoted compounds $(\sim 15$ in the nematic phase). This already suggests a strong antiferroelectric ordering of the dipoles.
It is interesting to perform a semi-quantitative comparison between the results we get and those of a homologous cyano compound of DB6 in which the direction of the COO bonds has been reversed [12] :

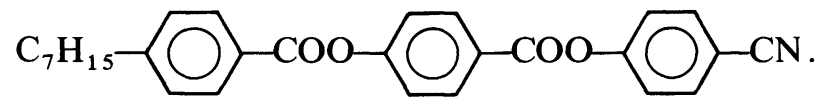

This compound has a $\mathrm{S}_{\mathrm{A}}-\mathrm{N}$ transition at $110^{\circ} \mathrm{C}$ and a N-I transition at $225^{\circ} \mathrm{C}$. Around $130^{\circ} \mathrm{C}$ the value of $\varepsilon_{\|}$is about 36 , i.e. much larger than in the case of DB6. One can calculate, following the naive method $\left({ }^{1}\right)$ of using the accepted values of the dipole bonds [13], the respective values of the molecular dipole $\mu_{\|}$parallel to the long axis. One finds $\mu_{\|}$ $(\mathrm{DB} 6) \simeq 3.37 \mathrm{D}$ and $\mu_{\|}$(homologous) $=5.23 \mathrm{D}$, i.e. the ratio of the parallel dipoles is 1.55 .

On the other hand, one can determine this ratio by means of the values of $\varepsilon_{\|}$in the nematic near the $\mathrm{N}-\mathrm{S}_{\mathrm{A}}$ transition, assuming that there are no strong translational correlations of the dipoles. We choose $T / T_{\text {NI }} \simeq 0.80\left(T \sim 175^{\circ} \mathrm{C}\right.$ for DB6 and $T \sim 125^{\circ} \mathrm{C}$ for the homologous compound) and we can assume without large errors that the nematic order parameter $S$ is nearly equal to 1 . We can write :

$$
\varepsilon_{\|}-\varepsilon_{\| x}=\frac{3 \bar{\varepsilon}}{2 \bar{\varepsilon}+\varepsilon_{\infty}} \frac{4 \pi N \mu_{\|}^{2}}{k T}
$$

using the results of reference [9] for the $\varepsilon_{\|}$component of the dielectric tensor of a perfectly ordered nematic. In the equation (1) $\bar{\varepsilon}$ is the mean value of the dielectric constant :

$$
\bar{\varepsilon}=\frac{\varepsilon_{\|}+2 \varepsilon_{\perp}}{3}
$$

We adopt a reasonable value of 2.5 for $\varepsilon_{\alpha}$ and with the help of (1), we get for the dipole ratio 2.3 . The difference with the upper value (1.55) can be easily explained by the existence of a strong specific antiferroelectric ordering of the DB6 molecules which considerably reduces the apparent molecular dipole moment.

In the range of frequency $0.1-100 \mathrm{MHz}$, we were only able to measure the parallel relaxations, when the electric measuring field is parallel to the director. In figure 3 , we show the variation of $\operatorname{tg} \delta$, where $\delta$ is the dielectric loss angle, at two different temperatures, one in the nematic phase and the second in the smectic A2 phase of the mixture DB6-TBBA. The stricking result is that we observe two relaxations and not only one like in others liquid crystals [12]. The two relaxations have very different behaviours.

As shown in figure 4, both systems present a slow thermal dependence of the low relaxation frequency $f_{\mathrm{R}}$ and concerning DB6 there is a change in the slope

$\left.{ }^{1}\right)$ The dipole moment of the molecule in its own medium is different of the dipole moment of the isolated molecule cf. Ref. [8]. 


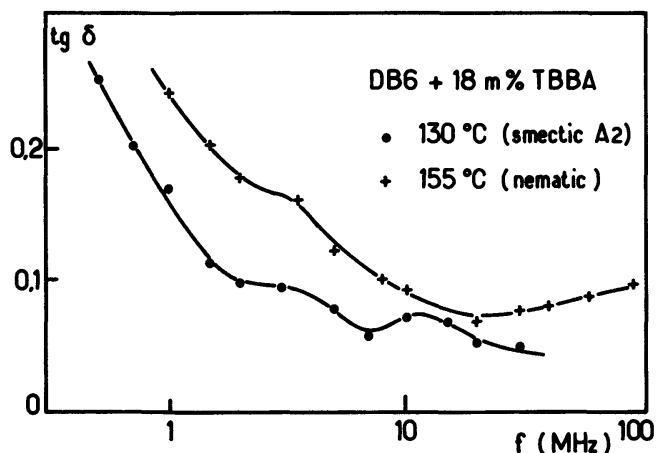

Fig. 3. - Tangent of the dielectric loss angle $(\mathbf{E} / / \mathbf{n})$ at different frequencies.

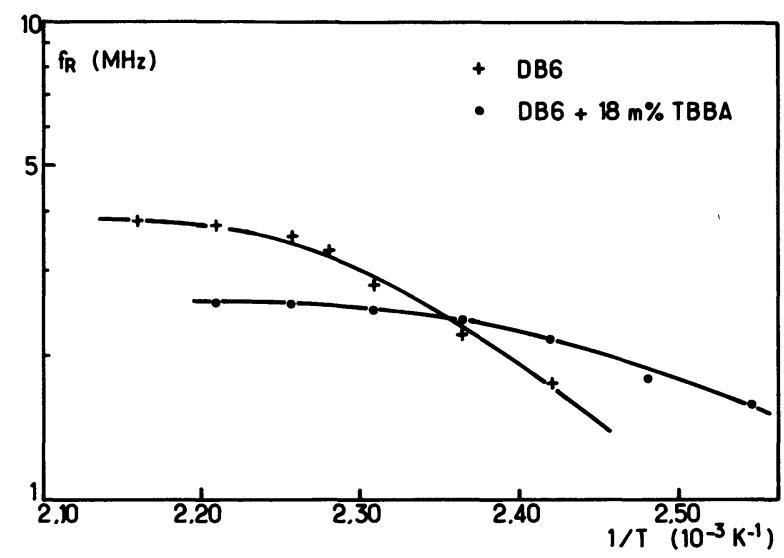

Fig. 4. - Relaxation frequency $f_{R}$ (logarithmic scale) versus inverse of the temperature. This corresponds to the lowest of the two relaxations observed on figure 3.

at the $\mathrm{N}-\mathrm{S}_{\mathrm{A} 2}$ transition temperature. In contrast, the second relaxation frequency $f_{\mathrm{R}}^{\prime}$ has a strong temperature dependence as in the others liquid crystal. Generally this latter relaxation is attributed to the flipping of the molecules around their short axis.
It is a rotational diffusive process with a well defined activation energy. The relaxation frequency $f_{\mathrm{R}}^{\prime}$ can be expressed as $f_{\mathrm{R}}^{\prime}=f_{0}^{\prime} \exp (-W / k T)$. For DB6-TBBA we found $f_{0}^{\prime}=5.5 \times 10^{21} \mathrm{~Hz}, W=1.16 \mathrm{eV}$, which are values comparable to those measured on other liquid crystals.

Thus this second relaxation has the characteristic of the flipping mechanism of the molecules, whereas the unusual temperature dependence of the first one suggests that $f_{\mathrm{R}}$ is associated with a quite different mode due to the antiferroelectric ordering. Perhaps it is a collective motion of the dipoles similar to those observed in the case of ferroelectric liquid-crystal at the $S_{A}-S_{C}^{*}$ transition $[14,15]$.

Furthermore, it is important to note that the results of the DB6-TBBA mixture are very similar to those concerning the pure DB6. This seems a little bit surprising since the appearance of the long-range antiferroelectric order takes place only in the $S_{A 2}$ phase where there is a doubling of the layer spacing. However as above seen for the DB6-TBBA system, anomalies in the dielectric constants appear at the $\mathrm{N}-\mathrm{S}_{\mathrm{A} 1}$ transition. In other words, by dielectric measurements, we cannot observe any difference in the $S_{A 1}$ and $S_{A 2}$ phases. Our results give support to the model of $S_{A 1}$ proposed by J. Prost [5]. The sample can be seen as an antiferroelectric ordered one but with many topological defects which destroy the bilayer character of the structure (figure 6 of reference [5])

To conclude, we have observed anomalies in the dielectric constants of systems which exhibit a bilayer structure in the low temperature $S_{A}$ phase $\left(S_{A 2}\right)$. The observation of two parallel relaxations is also characteristic of these samples, one of which is related to the antiferroelectric ordering. In fact, all these observations are in favour of a dipole ordering of antiferroelectric type and are in good agreement with the results of X-ray diffraction [7].

\section{References}

[1] Leadbetter, A. J., Frost, J. C., Gaughan, J. P., Gray, G. W., Mosley, A., J. Physique 40 (1979) 375.

[2] Cladis, P. E., Phys. Rev. Lett. 35 (1975) 48.

Hardouin, F., Sigaud, G., Achard, M. F., Gasparoux, H., Phys. Lett. 71A (1979) 347. Solid State Commun. 30 (1979) 265.

[3] Sigaud, G., Hardouin, F., Achard, M. F., Levelut, A. M., J. Physique 42 (1981) 107.

[4] Cladis, P. E., Bogardus, R. K., Daniels, W. B., TayLOR, G. N., Phys. Rev. Lett. 39 (1977) 720.

[5] Prost, J., Proceedings of the Conference on Liquid Crystals of one and two dimensional order, Garmish-Partenkirchen, (Springer Verlag, Berlin, Heidelberg, New-York) 1980, p. 125.

[6] Sigaud, G., Hardouin, F., Achard, M. F., Gasparoux, H., J. Physique Colloq. 40 (1979) C3-356.

[7] Hardouin, F., Levelut, A. M., Benattar, J. J., Sigaud, G., Solid State Commun. 33 (1980) 337.
[8] De Jeu, W. H., Goossens, W. J. A., BordewiJk, P., J. Chem. Phys. 61 (1974) 1985.

[9] Benguigui, L., J. Physique 40 (1979) 705. J. Physique 41 (1980) 341.

[10] Druon, C., WaCrenier, J. M., J. Physique 38 (1977) 47.

Lippens, D., Parneix, J. P., Chapoton, A., J. Physique 38 (1977) 1465.

[11] Benguigui, L., Hardouin, F., J. Physique Lett. 42 (1981) L-111.

[12] De Jeu, W. H., Liquid Crystals, L. Liebert ed., Solid State Phys. Suppl. no 14 (Academic Press, N.Y.) 1978, p. 109.

[13] Minkin, V. I., Osipov, O. A., Zhdanov, V. A., Dipoles Moments in Organic Chemistry (Plenum Press) 1970.

[14] Hoffman, J., KnCzynski, W., Malecki, J., Mol. Cryst. Liq. Cryst. 44 (1978) 287.

[15] Benguigui, L., Proceedings of the Conference on Liquid Crystals of one and two dimensional order, Garmish-Partenkirchen, (Springer Verlag, Berlin, Heidelberg, New-York) 1980 , p. 71 . 